\title{
EAl Endorsed Transactions

\section{A Case Study on the Development of Adult Language, Literacy and Numeracy Skills}

\author{
Mohiuddin Ahmed ${ }^{1, *}$ \\ ${ }^{1}$ School of Science, Edith Cowan University, Australia.
}

\section{Abstract}

Language, literacy and numeracy (LLN) are integral part of our lives, especially in workplace. In this paper, the current research on adult LLN practices are investigated. A case study based on a group of students' LLN scores are presented in this paper. The scores are analysed and appropriate support strategies are proposed to achieve the expected level of LLN for their qualification. There is a significant lack of research and methods to improve the LLN scores in the vocational sector to match the desired level of qualification and hence a case study in this area can be used as a reference. Additionally, the proposed approaches are purely based on classroom teaching and hence leaves a footprint to investigate further to identify ways to formalize these approaches. This contributions made in this paper will be helpful for academics and teaching staffs in the adult education sector. This paper can be used as a general reference for any qualification in the vocational education sector.

Keywords: Adult Education, LLN, Vocational Education

Received on 19 December 2018, accepted on 04 April 2019, published on 15 July 2019

Copyright ( 2019 Mohiuddin Ahmed et al., licensed to EAI. This is an open access article distributed under the terms of the Creative Commons Attribution licence (http://creativecommons.org/licenses/by/3.0/), which permits unlimited use, distribution and reproduction in any medium so long as the original work is properly cited.

doi: 10.4108/eai.30-10-2018.159602

\section{Introduction}

Language, literacy and numeracy (LLN) skills define the way we communicate. These skills are often used simultaneously but not always. These skills are the key components in any job role now-a-days and therefore for designing a training program, we need to consider the level of LLN skills required, not only to participate in the program but to perform effectively in the workplace [9]. Specially, in the Vocational Education and Training (VET) sector, the delivery and assessment of a training program ensures that a learner has all the support for LLN issues. For adult learners, LLN is more important because they are playing pivotal role in their workplaces and if the LLN issues are not handled correctly then it may impact their work and organization as a whole. Unlike Australian Core Skills Framework (ACSF), LLN encompasses an adult's abilities to function effectively in the workplace [1].

Every training package includes information on employability skills and foundation skills, which are completely based on language, literacy and numeracy. in addition to that, the Australian Qualification

*Corresponding author was affiliated with the Centre for Cyber Security and Games at Canberra Institute of Technology during the initial submission of this manuscript. Email: m.ahmed.au@ieee.org
Framework (AQF) provides general guidance on the level of performance expected of a learner within qualification levels Certificate I through to Advanced Diploma (only in VET). Where, Certificate I having very basic entry level skill and knowledge requirements and a Diploma or Advanced Diploma having much higher expectations of entrants [2]. In contrast, ACSF is more focussed on the level and depth of an individual's abilities in a range of core skills such as LLN. The ACSF provides the foundations and benchmarks for the development of training plans based on the individual's abilities rather than qualification requirements which is crucial in VET sector [3].

An interesting case study on LLN development is published in 2018 focussing on the developing countries [4]. The study suggested to provide more resources to both the teachers and students to enhance the LLN skills in the early stage of education life. In another recent paper [5], the authors discussed impact of NAPLAN test in remote Australian indigenous communities.

The Business Council of Australia and the Australian Chamber of Commerce and Industry produced the Employability Skills for the Future report in 2002. Although its been more than 15 years, the insights 
gained from the report are still valid. According to Victoria state government education and training department [1], it is identified that there are eight key employability skills which a candidate must possess along with relevant job skills. These eight key skills are outlined in the Table 1.

\subsection{Roadmap}

The rest of the paper is organized as follows. Section 2 analyses LLN and discusses the LLN scores of five students using the LLN test robot. Section 3 contains support plan and development strategies for each of the core skills for the students whose LLN scores are below the expected ACSF level. Section 4 depicts the customized learning resources that will enhance the LLN skills of the students. The paper is concluded in Section 5.

\section{LLN Analysis}

As mentioned earlier, the ACSF contains the standards for LLN which needs to be reflected in the relevant training packages [6] are summarized below:

- Language: is the primary means by which we understand meaning as humans. According to wikipedia [7], Language is a system that consists of the development, acquisition, maintenance and use of complex systems of communication, particularly the human ability to do so; and a language is any specific example of such a system. Language at workplace helps ourselves to attain personal, work and social goals.

- Literacy: is the application in our daily life, not only in workplace. It is the ability to understand information and act upon it. Literacy encompasses the speaking, listening and critical thinking with reading and writing. It is the primary method to interact with one another [1].

- Numeracy: is the ability to use the mathematical concepts needed to perform efficiently in work place and in social contexts [1]. For example, how to calculate the monthly expenditure, how to manage the salary from work etc. In a nutshell, it involves the hand-on application of mathematical skills to absorb, use and critically evaluate information in numerical or graphical form [1]. Based on the context numeracy requires number skills, spatial and graphical concepts, the use of measurement and problem solving.

\subsection{LLN Test Result}

The Table 2 showcases the LLN scores of the five students from a course, Design Systems for Diploma of Information Technology and Software Development [13]. Here, the LLN robot is used which is an online system that combines ACSF testing, Course profiling and LLN Support into one easy to use package [3].

The group of students who participated in the LLN test contain both local and international students. It is an important way to identify the LLN skills of the students coming from non-English speaking background. From the Table 2, it is visible that, all the students have identical scores, however, each of the students will have to reach level 4 from current level 3 to be able to qualify for the Diploma of Software Development. In addition, according to the experienced teaching professionals in VET sector, for the design systems subject, the expected LLN level is 4 . Therefore, it is important to devise strategies to enhance the LLN skills of this cohort and future students as well.

\section{Support Plan}

The job of an instructor is to introduce effective strategies to the learners to successfully overcome the LLN issues. Below are the approaches to support students[11].

- Identify the learner's preferred learning style and design training based on those strengths.

- Identify the learning difficulties and research to find solutions.

- Understand their requirements

- Follow all of the above

Although there are plethora of research on LLN, the individual needs are quite unique and therefore providing support is not always straightforward[10]. It is important that, the instructors are proactive and devise strategies based on the learner's strengths and always supportive when the learner faces any difficulty. Next, the strategies followed for the group of student's LLN improvement will be explained briefly.

\subsection{Strategies for Learning Development}

The test results from Table 2 indicate that they need to develop their Learning skills based on the course they are enrolling in. It is recommended that throughout the training the learner is given opportunities to carry out 
Table 1. Employability skills from the Business Services Training Package and how these relate to ACSF core skills [1]

\begin{tabular}{|c|c|c|}
\hline Skill & Industry Requirement & Core Skill \\
\hline Communication & $\begin{array}{l}\text { Verbal communication for negotia- } \\
\text { tion, questioning and training }\end{array}$ & $\begin{array}{l}\text { Oral communication, Writ- } \\
\text { ing, Learning }\end{array}$ \\
\hline Technology & $\begin{array}{l}\text { using state-of-the-art technology to } \\
\text { communicate }\end{array}$ & $\begin{array}{l}\text { Oral communication, } \\
\text { Learning, Reading, Writing, } \\
\text { Numeracy. }\end{array}$ \\
\hline Problem-solving & resolving conflicts and issues & $\begin{array}{l}\text { Learning, Reading, Writing, } \\
\text { Numeracy, Oral Communi- } \\
\text { cation }\end{array}$ \\
\hline Initiative & $\begin{array}{l}\text { demonstrating individual responsi- } \\
\text { bility for completing tasks }\end{array}$ & $\begin{array}{l}\text { Learning, Reading, Writing, } \\
\text { Numeracy, Oral Communi- } \\
\text { cation }\end{array}$ \\
\hline Planning & $\begin{array}{l}\text { contributing to planning processes } \\
\text { to meet expected outcomes }\end{array}$ & $\begin{array}{l}\text { Learning, Reading, Writing, } \\
\text { Numeracy, Oral Communi- } \\
\text { cation }\end{array}$ \\
\hline Self-management & $\begin{array}{l}\text { detecting professional development } \\
\text { requirements and seeking opportu- } \\
\text { nities }\end{array}$ & $\begin{array}{l}\text { Learning, Reading, Writing, } \\
\text { Numeracy }\end{array}$ \\
\hline Learning & 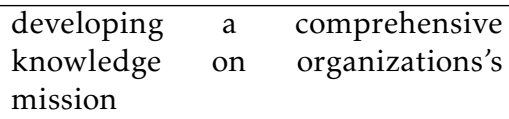 & $\begin{array}{l}\text { Learning, Reading, Writing, } \\
\text { Numeracy }\end{array}$ \\
\hline Teamwork & $\begin{array}{l}\text { completing individual tasks to sup- } \\
\text { port team goals }\end{array}$ & $\begin{array}{l}\text { Oral communication, Writ- } \\
\text { ing }\end{array}$ \\
\hline
\end{tabular}

Table 2. LLN Test Results of Diploma of Software Development Students [3]

\begin{tabular}{|l|c|c|c|c|c|}
\hline Student & Learning & Reading & Writing & Oral Comm. & Numeracy \\
\hline Student-1 & 3 & 3 & 3 & 3 & 3 \\
\hline Student-2 & 3 & 3 & 3 & 3 & 3 \\
\hline Student-3 & 3 & 3 & 3 & 3 & 3 \\
\hline Student-4 & 3 & 3 & 3 & 3 & 3 \\
\hline Student-5 & 3 & 3 & 3 & 3 & 3 \\
\hline \hline Expected & 4 & 4 & 4 & 4 & 4 \\
\hline
\end{tabular}

the following tasks to support the development of their skills to ACSF level 4 in Learning:

- Seek feedback from experienced persons to improve their level of performance and support the development of their skills.

- Act in a leadership role as part of a group exercise which includes some organisation and problem solving.

- Access and use software and computer systems to locate or use relevant information.

- Use email, blogs, internet, wikis, discussion boards and forums to support the learning experience.
- Use the internet to conduct in-depth research for a complex task or topic.

These tasks (extracted from training recommendations) will assist the learner to develop leadership, research, organisation, time management, problem solving and technology or digital literacy skills. An interesting thesis is currently available on the adult learning improvement [8].

\subsection{Strategies for Reading Development}

Reading is considered as the most important aspect of LLN as it requires in majority of the skills such as problem solving, planning, self-management, technology etc. [10]. Below are the list of recommended strategies to enhance the current skill level of the 
students who require further improvements:

- Read a range of texts written from different perspectives to form an opinion about a central idea or topic.

- Access technical texts relevant to job role and relevant technology to improve understanding and knowledge of a process.

- Read and reflect on the usefulness of different texts to meet a specific purpose. This includes identifying relevance, bias and currency.

- Identify and use specialised vocabulary and acronyms relevant to subject of study.

- Access complex or technical texts that require the consideration of theoretical information or situations to infer a reasonable conclusion based on evidence and reflection (e.g. legislation, codes of practice, statistical information, complex reports, evaluations and assessments).

These aforementioned tasks will assist the learner to develop reading, research and critical thinking skills.

\subsection{Strategies for Writing Development}

In diploma level, being able to write effectively is an important requirement for the qualification as well as the core skill framework. According to the [11], following strategies are useful for supporting the writing improvements:

- Develop an induction manual, or standard operating procedure or users/operational manual for a task or piece of equipment.

- Document the roles, responsibilities and time frames for a project.

- Compile reports or plans that use a range of sources or services.

- Write a series of instructions for a team or group to complete a task.

- Prepare texts intended for different audiences and purposes utilising appropriate language, format graphics.

- Prepare a report containing tables, data and graphs comparing results over a period of time, locations or groups and prepare recommendations based on the findings.

The assessment tasks and classroom activities are designed to emphasise on the writing skills of the students.

\subsection{Strategies for Oral Communication Development}

Oral communication is an important aspect for employment in today's competitive market. Being able to communicate different ideas is the most sought after skill in information technology industry nowa-days [12]. Below are the actions recommended to enhance the oral communication skill of the students:

- Discuss the causes of a problem with workmates or classmates and work out a solution.

- Provide in-depth verbal feedback on their experience in the course.

- Provide verbal instructions for a process to the members of a group, selecting appropriate language for the audience.

- Participate in discussions and meetings.

- Follow a sequence of instructions given verbally for a task or piece of equipment they are not familiar with.

- Listen and take notes during training sessions.

In majority of the lectures, there are individual and group activities where the students have to present their work. That ensures the oral communication skills.

\subsection{Strategies for Numeracy Development}

In the ACSF there are three indicators for numeracy [11]. The indicators are listed below:

- how mathematical concepts are embedded in spoken and written text

- the skills of problem-solving and using mathematical processes

- the skills of using the specific symbols to communicate.

These are concerned with the representation of mathematical concepts embedded in text and the specific symbols and representation of mathematical concepts [11]. Below are the recommended strategies to be followed:

- Complete routine algebraic formulas as part of their work (capacity, volume, area, circumference etc.).

- Extract relevant information from statistical data in complex tables, spreadsheets and graphs and calculate mean, median and mode).

- Use in-the-head calculations or estimations, pen and paper calculations and use a calculator across a range of activities. 
- Apply scale or ratio to a map, physical space or quantities.

- Use a range of techniques to calculate travel distance or travel times using maps.

- Apply percentages, decimals and fractions and work out the equivalent of each (e.g. $\frac{2}{5}=0.4=$ $40 \%)$.

The aforementioned strategies are embedded in my lectures to help the students hone their numeracy skills.

\section{Customized Learning Resource}

For the Design Systems subject, the contents are designed considering the unit of competencies and required LLN level according to ACSF. However, once the gap in LLN skills are identified, the resources can be modified to suit the learner's need. Table 3 showcases a mapping of the key lectures for the design systems subject with the core LLN skills. Since the learners were taught face to face, the trainer (myself) had fair chances to apply different strategies for teaching, specially, evidence based teaching focussing on Questioning to Check for Understanding. The teacher should try to routinely check for understanding of the students throughout the class. The teaching philosophy lies on the famous saying that "knowledge is power" and the same topic should not be repeated time and again since it is wastage of time for both the students and teacher. Therefore, it is imperative that, the teacher checks the understanding of students. Even if there are few shy students, the checking will help them a lot to clarify their knowledge.

Once a particular topic is finished discussing in the class, some questions relevant to the topic should be thrown and try to engage the students in brainstorming. It provides instant feedback of teaching and at the same time the students are able to gain a thorough understanding of the topic and whether they are ready to move on. Effective training and assessment practice requires to use trainer's own LLN skills to demonstrate the expectation in workplace context by providing explanations and examples. It is also important to involve the students in the learning process and modifying/reinforcing as time passes [11].

\subsection{Customized Assessment Tasks}

To enhance the LLN levels of the students, all the assessment tasks can be revised for the subject. Additionally, to provide the students more scope to work on the assessment tasks, the students can be encouraged to work on the classroom exercises which are relevant to the assessment tasks. Practicing in the classroom enhances their LLN skills significantly and they can submit the final assessment tasks with greater confidence.

- Written short answer: Some learners will find writing stressful if it has to be done under test conditions, i.e. the assessment task- 3 for this subject is timed. Therefore, it is a good idea to include practice runs of the similar tasks when there is no pressure, for example as a classroom exercise which is not marked or assessed to effect the final grades.

- Extended written responses: Extended written tasks are in the form of an essay or a report. For the design system subject, one of the assessments require the students to go through a case study and then analyse and provide solutions as a consultant. This assessment requires the students to write in professional format which gives them a chance to enhance their writing skills.

- Spoken presentations: Public speaking is not a cup of tea for everyone. However, an important skill to thrive in the work place. In the class, plenty of opportunities for the students to present in class without pressure can be provided.

- Individual or group projects: These type of activities are useful for holistic assessment as well as to improve the LLN skills. The students are often asked to work in groups for classroom exercises after the lecture.

- Design from a case: Another effective way to enhance the LLN skills is to engage the students to work on their design tasks in classroom which will help the students to reach the adequate level for the qualification.

The Table 4 reflects the mapping of the three assessment tasks for the design systems subject with the core skill sets.

\subsection{Monitoring Performance}

In terms of LLN, it is imperative to have an effective monitoring program in place. Monitoring will ensure the successful outcome of the LLN improvisation process for the learners. Throughout the process, the data gathered will be based on a number of issues such as the program, learner needs, policy and procedure. According to [11], it is important to continuously 
Table 3. Mapping of the key Lectures with Core Skills [13]

\begin{tabular}{|c|c|c|c|c|c|}
\hline Lecture & Reading & Writing & Oral & Numeracy & Learning \\
\hline Concepts of Design Systems & & & & $\checkmark$ & $\checkmark$ \\
\hline Business Use Case & & & & $\checkmark$ & $\checkmark$ \\
\hline Analysis Use Case & & & & $\checkmark$ & $\checkmark$ \\
\hline Design Use Case & & & & $\checkmark$ & $\checkmark$ \\
\hline Business Case & & & $\checkmark$ & $\checkmark$ & $\checkmark$ \\
\hline User Interface Design & & $\checkmark$ & & & $\checkmark$ \\
\hline Development Strategies & $\checkmark$ & & & $\checkmark$ & $\checkmark$ \\
\hline Data Design & $\checkmark$ & & & $\checkmark$ & $\checkmark$ \\
\hline System Architecture & $\checkmark$ & & & & $\checkmark$ \\
\hline Systems Support & & & $\checkmark$ & & $\checkmark$ \\
\hline Systems Implementation & & & $\checkmark$ & $\checkmark$ & $\checkmark$ \\
\hline Stakeholder Management & $\checkmark$ & $\checkmark$ & $\checkmark$ & $\checkmark$ & $\checkmark$ \\
\hline
\end{tabular}

Table 4. Mapping of the Assessment Tasks with Core Skills

\begin{tabular}{|l|c|c|c|c|c|}
\hline \multicolumn{1}{|c|}{ Skill } & Learning & Reading & Writing & Oral & Numeracy \\
\hline Tassessment & $\checkmark$ & & & $\checkmark$ & $\checkmark$ \\
\hline Task-2: Business Case & $\checkmark$ & $\checkmark$ & $\checkmark$ & & $\checkmark$ \\
\hline Task-3: Final Knowledge Test & $\checkmark$ & $\checkmark$ & & $\checkmark$ & $\checkmark$ \\
\hline
\end{tabular}

follow up with the students at LLN risks to meet the gap between the current level and expected level.

\section{Conclusions}

This paper explores the different ideas and strategies to address the adult LLN requirements. A group of students were tested with LLN robot and the scores were not in the desired level of the qualification. As a case study, in this paper, appropriate support strategies and learning resources requirement were developed and customized to address the needs of those students.

\section{References}

[1] Address adult language, literacy and numeracy skills. Retrieved from https://www.education.vic.gov.au

[2] Australian Qualification Framewrok. Retrieved from https://www.aqf.edu.au/

[3] LLN Robot: Learner Resutls. Retrieved from https://cit.lln.training/admin/learnerresults

[4] Benjamin Piper, Stephanie Simmons Zuilkowski, Margaret Dubeck, Evelyn Jepkemei, and Simon J. King. Identifying the essential ingredients to literacy and numeracy improvement: Teacher professional development and coaching, student textbooks, and structured teachers' guides. World Development, 106:324 - 336, 2018.

[5] Susy Macqueen, Ute Knoch, Gillian Wigglesworth, Rachel Nordlinger, Ruth Singer, Tim McNamara, and Rhianna
Brickle. The impact of national standardized literacy and numeracy testing on children and teaching staff in remote australian indigenous communities. Language Testing, 0(0):1-20, 2018.

[6] The Crux of the Matter 2011: Language, Literacy and Numeracy and Vocational Education and Training. Retrieved from https://training.qld.gov.au

[7] Language in Wikipedia. Retrieved from https://en.wikipedia.org/wiki/Language

[8] Russell D. Mason. Improving outcomes for adult learners. Master's thesis, Queens- land University of Technology, 2016.

[9] Rogers-Shaw, C., Carr-Chellman, D. J., and Choi, J. (2018). Universal Design for Learning: Guidelines for Accessible Online Instruction. Adult Learning, 29(1), 20-31.

[10] The Key to Comprehension: Teaching Reading Strategies. Retrieved from https://online.seu.edu/teachingreading-strategies/

[11] Fresh Ideas in Training. Retrieved from http://www.hia.edu.au/

[12] Lacy M. Cleveland and Robert J. Reinsvold. Development of Oral Communication Skills by Undergraduates that Convey Evolutionary Concepts to the Public. Journal of Microbiology and Biology Education, 18:1-25, 2017.

[13] Whitten L.Jeffrey and Bentley D. Lonnie and Dittman C. Kevin. Systems analysis and design methods Boston, Mass. : Irwin/McGraw-Hill, 2001. 